\title{
STUDI DISTRIBUSI TEKANAN ALIRAN MELALUI PENGECILAN SALURAN SECARA MENDADAK DENGAN BELOKAN PADA PENAMPANG SEGI EMPAT
}

\author{
Sarjito, Subroto, Arif Kurniawan \\ Jurusan Teknik Mesin Fakultas Tekknik Universitas Muhammadiyah Surakarta Jl. A Yani, \\ Pabelan, Kartosuro, Tromol Pos I, Surakarta. Telp. (0271) 715448. \\ E-mail :sarjito@ums.ac.id
}

\begin{abstract}
ABSTRAK
Tujuan dari penelitian ini adalah mempelajari distribusi tekanan dan penurunan tekanan pada aliran satu fase, melalui penampang pipa persegi dengan belokan (elbow) dan mengalami pengecilan saluran (sudden contraction) ditinjau dari berbagai sudut pandang. Rasio pengecilan saluran yang dipakai adalah $S=0.6, S=0.667$ dan $S=0.8$

Penelitian dilakukan dengan mengalirkan fluida melalui rotameter sebelum masuk seksi uji. Kemudian, Debit aliran yang dipakai sebagai parameter yang divariasi dalam penelitian ini, yaitu 2 gpm, 4 gpm dan 8 gpm. Dengan mnggunakan fluida satu fase yang berupa air. Titik pengukuran tinggi tekanan diambil pada bagian dinding depan dan dinding samping seksi uji. Pada bagian depan seksi uji, diambil 15 titik pengukuran sebelum dinding kontraksi dan 15 titik pengukuran sesudah dinding kontraksi. Pada bagian dinding samping seksi uji, diambil 9 titik pengukuran sebelum dinding kontraksi dan 9 titik pengukuran sesudah dinding kontraksi.

Penelitian menghasilkan bahwa setiap kenaikan kecepatan selalu diikuti dengan penurunan tekanan, begitu juga sebaliknya. Pada pipa $(S)=0,6$ dengan debit 8gpm, sebelum kontraksi mempunyai kecepatan $\left(v_{\nu}\right)=0.0683 \mathrm{~m} / \mathrm{s}$ dan tekanan $109 \mathrm{Kg} / \mathrm{m}^{2}$ pada sumbu saluran (titik 3c), kemudian setelah melewati dinding kontraksi tekanan turun menjadi $-30 \mathrm{Kg} / \mathrm{m}^{2}$ pada kecepatan aliran $\left(v_{2}\right)=0.1896 \mathrm{~m} / \mathrm{s}$. Ketika aliran mendekati sudut belokan $\left(90^{\circ}\right)$ terjadi peningkatan tekanan karena adanya perlambatan aliran. Debit aliran berpengaruh pada besarnya tekanan, semakin besar debit aliran semakin besar juga tekanan yang dapat di ukur. Pada debit aliran (Q) 4 GPM dalam saluran rasio 0,667, aliran masuk bertekanan $85 \mathrm{Kg} / \mathrm{m}^{2}$ ketika debit dinaikkan menjadi 8 GPM tekanan naik menjadi $133 \mathrm{Kg} / \mathrm{m}^{2}$. Namun semakin jauh posisi aliran dari dasar pipa maka akan semakin kecil tekanannya. Semakin besar luas penampang pipa maka akan semakin kecil Bilangan Reynoldsnya, untuk rasio pengecilan 0,6 pipa outlet ( $A=$ $0.0025 \mathrm{~m}^{2}$ ) pada $Q=0.000171 \mathrm{~m} 3 /$ det diperoleh harga $R e=3379.53795$, pada rasio pengecilan 0,667 $\left(A=0.0016 \mathrm{~m}^{2}\right)$ pada $Q=0.000171 \mathrm{~m}^{3} /$ det diperoleh harga $\operatorname{Re}=$ 4224.42244 dan untuk rasio pengecilan 0,8 pipa outlet $\left(A=0.0016 \mathrm{~m}^{2}\right)$ pada debit $(Q)$ $=0.000171 \mathrm{~m}^{3} /$ det diperoleh harga Re $=4224.42244$. Bilangan Reynolds juga akan naik seiring dengan besarnya debit aliran.
\end{abstract}

Kata kunci : penampang persegi, air, belokan (elbow), pengecilan saluran (sudden contraction).

\section{PENDAHULUAN}

Peran fluida sangat penting dalam kehidupan manusia, baik sebagai alat penunjang untuk mempermudah aktifitas maupun dalam sirkulasi cairan tubuh manusia itu sendiri. Sebagai 
alat penunjang, fuida sering dipakai dalam berbagai bidang industri untuk Transportasi hidrolik, demikian juga dalam industri kimia, perminyakan, PDAM dan lain-lain. Hal ini mempunyai beberapa keuntungan antara lain : ramah terhadap lingkungan, peralatan relatif sederhana, biaya operasi dan perawatan yang murah. Dan proses pemindahan fluida umumnya dilakukan melalui suatu media berupa jaringan pipa atau sistem pipa.

Pipa merupakan saluran tertutup yang biasanya berpenampang lingkaran dan digunakan untuk mengalirkan fluida dengan tampang aliran penuh. Fluida yang dialirkan melalui pipa bisa berupa zat cair atau gas, tekanan bisa lebih besar atau lebih kecil dari tekanan atmosfir [1]. Dalam sistem pipa, banyak sekali persoalan yang dialami oleh aliran didalamnya. Salah satunya adalah masalah pengecilan penampang secara mendadak. Selain itu, juga ada masalah pembelokan dari system jaringan pipa itu sendiri. Dan ini sangat berpengaruh terhadap lancar tidaknya aliran didalam pipa. Tentunya juga mempengaruhi efisiensi dan produktifitas dalam industri.

Berbagai penelitian telah banyak dilakukan untuk mengkaji perubahan pola aliran terhadap perubahan bentuk penampang dan dimensi saluran, hal ini dilakukan untuk mengetahui berbagai karakteristik pola aliran yang terjadi pada saluran pipa. Disini peneliti mencoba mencari variasi baru dari system perpipaan, yaitu dengan menggunakan pipa berpenampang persegi dengan melalui pengecilan saluran secara mendadak dan belokan. Sepengetahuan peneliti riset tentang hal ini be um banyak dilakukan.

\section{PERUMUSAN MASALAH}

Permasalahan dalam penelitian ini adalah bagaimana kondisi karakteristik aliran fluida air (satu fase) ketika dialirkan dengan mengalami pengecilan panampang secara mendadak (sudden contraction) dan dilewatkan pada sebuah belokan (elbow) dengan sudut $90^{\circ}$ ?

\section{BATASAN MASALAH}

Ruang lingkup penelitian yang akan dilakukan, yaitu :

1. Eksperimen dibatasi hanya untuk aliran satu fase dengan menggunakan fluida cair berupa air bersih.

2. Pipa yang digunakan adalah saluran pipa persegi dengan belokan vertikal ke atas yang berupa pengecilan mendadak (sudden contraction).

3. Analisis pola aliran dan perilaku dinamika fluida pada saluran atau instalasi dilakukan dengan cara eksperimental.

4. Variasi parameter dan benda uji dilakukan pada posisi saluran pengeluaran setelah rotameter.

\section{TUJUAN PENELITIAN}

Tujuan penelitian ini adalah untuk mengetahui distribusi tekanan dan penurunan tekanan yang terjadi pada fluida air (satu fase) ketika dilewatkan pada saluran penampang persegi dengan belokan dan mengalami kontraksi saluran.

\section{TINJAUAN PUSTAKA}

Sumarli (2000) [2], melakukan penelitian aliran fluida air dalam pipa persegi yang mengalami kontraksi mendadak. Penelitian ini menunjukkan bahwa pada daerah transisi sebelum dinding kontraksi, tekanan statik pada batas saluran lebih besar dibanding tekanan pada sumbu saluran. Sedangkan setelah melewati dinding kontraksi, tekanan static pada batas saluran lebih rendah dibanding tekanan pada sumbu saluran, hal tersebut ditunjukkan pada gambar 1. 


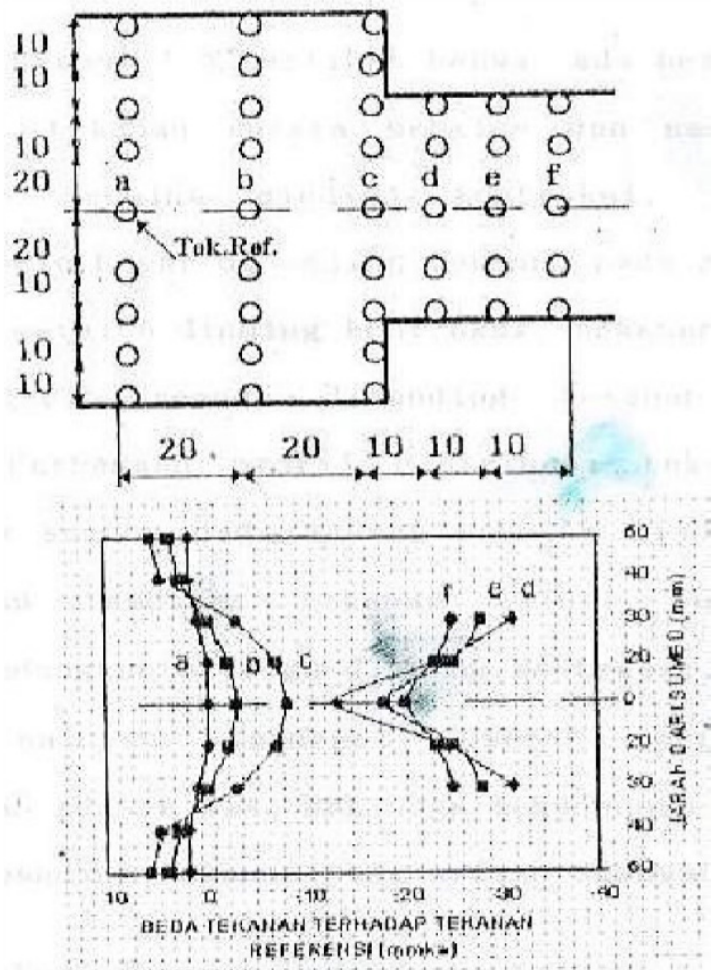

Gambar 1. Distribusi tekanan arah tegak lurus sumbu saluran. [2]

Harjanto (2003) [3] melakukan eksperimen untuk menguji kekasaran pipa pada beberapa produk yang berlainan dan diameter yang berbeda, kesimpulan yang didapat dari hasil perhitungan dan analisisnya adalah :

1. Koefisien gesekan pada saluran pipa PVC berbanding terbalik dengan kerugian tenaga aliran.

2. Koefisien gesekan pada saluran dipengaruhi oleh kecepatan, tekanan serta laju aliran volumetrik.

3. Apabila debit naik, angka Reynolds pun naik, begitu juga beda tekanan dan rugi head.

4. Semakin kecil luas penempang yang dilewati aliran fluida semakin besar kerugian gesekan yang terjadi

\section{Aliran Fluida Melalui Pengecilan Saluran dan Mengalami Belokan.}

Pada gambar 2 bagian atas ditunjukkan garis arus atau streamline pada batas dinding saluran. Garis arus adalah garis yang setiap saat menjadi tempat singgungan vektor-vektor kecepatan. Pada saat memasuki daerah transisi (penampang 1), aliran mulai memisahkan diri dari dinding saluran dan mengalami kontraksi sampai pada luas aliran terkecil yang disebut vena Contracta (penampang 3). Setelah itu, aliran mengalami ekspansi sampai pada penampang 4 dimana aliran yang sebelumnya terpisah lalu bertemu kembali dengan dinding saluran sehingga aliran memenuhi luasan saluran. 


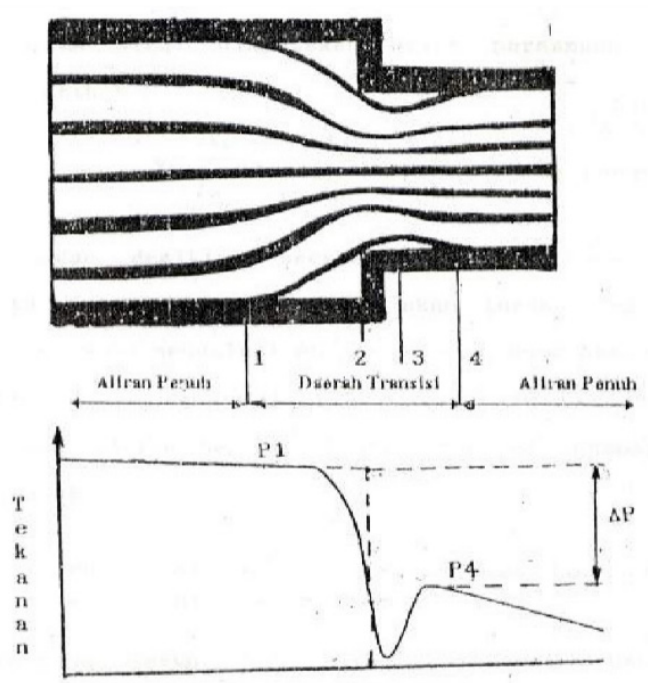

Gambar 2. Garis Alir pada Batas [4]

\section{Saluran dan Tekanan pada Sumbu Saluran}

Menurut hukum kekekalan energi perubahan pada salah satu bentuk energi akan diikuti oleh perubahan pada bentuk energi yang lain. Hubungan antara perubahan tekanan dan kecepatan dinyatakan dalam persamaan Bernoulli sebagai berikut :

$$
\frac{p_{1}}{\rho g}+\frac{v_{1}^{2}}{2 g}+z_{1}=\frac{p_{2}}{\rho g}+\frac{v_{2}^{2}}{2 g}+z_{2}
$$

Dengan demikian secara teoritis aliran yang mengalami percepatan, tekanannya akan turun. Sedangkan pada aliran yang mengalami kecepatan rendah (ekspansi) tekanannya akan naik. Oleh karena itu secara teoritis gambar profil tekanan pada sumbu saluran seperti ditunjukkan pada gambar 2. bagian bawah. Dalam penyempitan mendadak kerugian kecil timbul antara penampang I dan II (Gambar 3), dimana aliran memencar. Pada penampang II sebuah vena contracta terbentuk, dalam hal lain kalau pemasukan ke pipa yang lebih kecil dilengkungkan dengan baik, maka kerugian dikurngi benar sampai nol sehingga tidak terbentuk vena contracta.

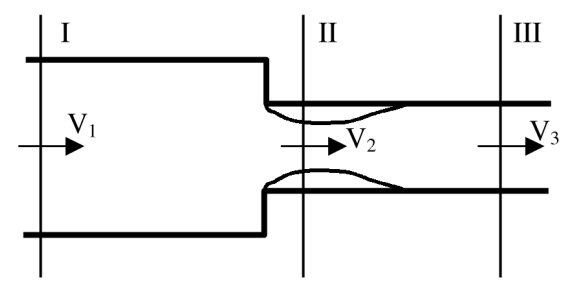

Gambar 3. Pengecilan Mendadak [4]

\section{Penurunan Tekanan}

Penurunan tekanan (Pressure drop) dapat disebabkan oleh adanya gesekan, gravitasi, belokan dan perubahan kecepatan.

\section{Pengukuran Tekanan}

Fluida yang mengalir dalam saluran memiliki empat macam tekanan, yaitu sebagai berikut:

1. Tekanan statik (P) adalah tekanan yang diukur pada arahnya tegak lurus aliran. Untuk 
menentukan tekanan ini, dapat digunakan Persamaan Hidrostatik berikut :

$\mathrm{P}=\mathrm{P}^{\mathrm{o}}+\mathrm{h} \gamma 2$ Terlihat, tekanan statik terdiri dari tekanan-luar $\left(\mathrm{P}^{\circ}\right)$ yang bekerja pada bidang batas zat cair dan tekanan akibat beratnya zat cair yang berada diatas luasan yang kita tinjau.

2. Tekanan dinamik $\left(\mathrm{P}_{\mathrm{v}}\right)$ ada ah tekanan yang besarnya ekuivalen dengan energi kinetik.

3. Tekanan stagnasi $\left(\mathrm{P}_{\mathrm{o}}\right)$ adalah tekanan yang merupakan jumlah dari tekanan statik dengan energi kinetik.

Dalam penelitian ini tekanan yang diukur adalah tekanan statik. Cara mengukur tekanan statik adalah dengan membuat lubang berdiameter $3 \mathrm{~mm}$, kemudian menghubungkan lubang tersebut dengan pipa manometer. Tinggi air dalam pipa manometer menunjukkan tekanan statik pada lubang yang diukur. Jika dalam membuat lubang tidak benar, misalnya posisinya tidak tegak lurus aliran, maka hasil pengukurannya tidak akan akurat. Beberapa contoh pembuatan lubang yang salah ditunjukkan pada gambar 4. Pada gambar 4 disebutkan bahwa penempatan lubang pada dinding yang tidak rata dapat menghasilkan tekanan yang lebih rendah atau lebih tinggi dari tekanan statik yang sebenarnya.

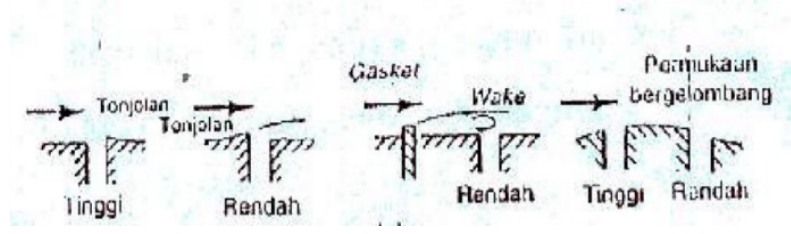

Gambar 4. Lubang Pengukuran Tekanan yang Salah. [5]

Misalnya pada permukaan yang bergelombang, lubang yang ditempatkan sebelum permukaan menonjol menghasilkan tekanan yang tinggi. Sedangkan lubang yang ditempatkan sesudah permukaan menonjol menghasilkan tekanan yang rendah. Hal ini dikarenakan permukaan saluran yang menonjol menyebabkan terjadinya perubahan arah garis arus sehingga posisi lubang tidak lagi tegak lurus pada arah aliran. Gambar 5 menunjukkan pembuatan lubang pengukuran yang benar.

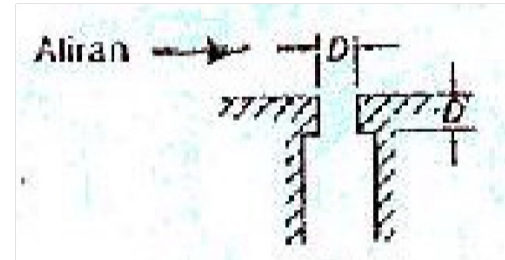

Gambar 5. Lubang Pengukuran Tekanan yang Benar. [5] 


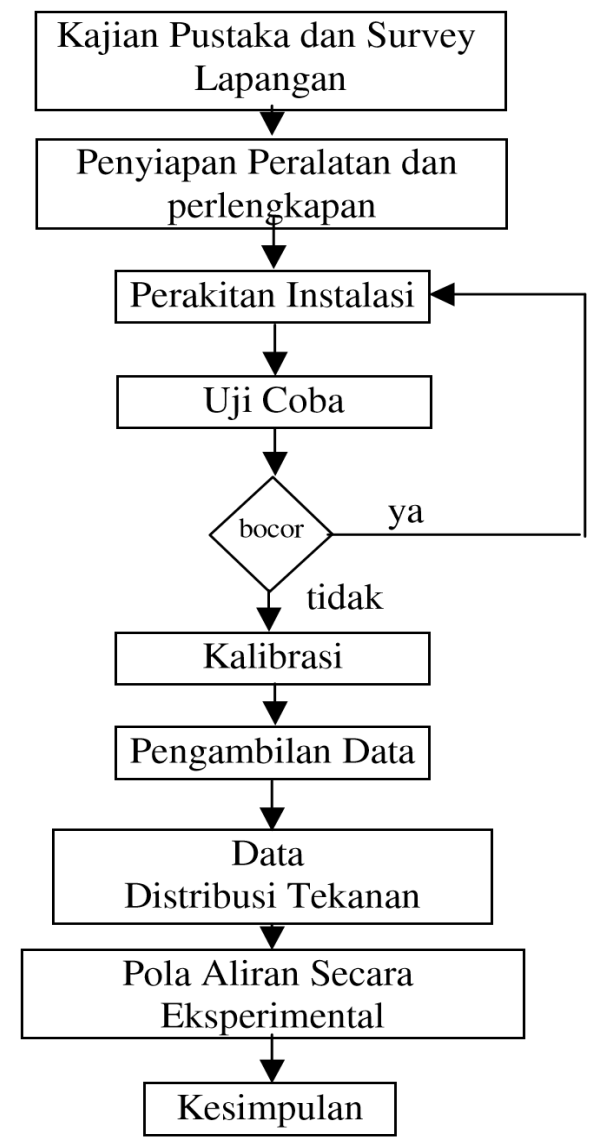

Gambar 6. Diagram Alir Penelitian

\section{Seksi Uji}

a. Bahan pembuatan seksi uji :

1. Plexiglass lembaran dengan ukuran $1700 \mathrm{~mm}$ X $980 \mathrm{~mm}$, tebal $5 \mathrm{~mm}$.

2. Resin 108 (bening super).

3. Katalis.

4. Lem silicon.

5. Lem acrylic

b. Proses Pembuatan Seksi Uji

Dalam penelitian ini, seksi uji dibuat dengan panjang total kurang lebih $1600 \mathrm{~mm}$. Mula-mula plexiglass lembaran dengan ukuran $1700 \mathrm{~mm}$ x $980 \mathrm{~mm}$ dipotong dengan ukuran $60 \mathrm{~mm}$ sebanyak 4 lembar, $50 \mathrm{~mm}$ sebanyak 8 lembar, $40 \mathrm{~mm}$ sebanyak 8 lembar, dan $30 \mathrm{~mm}$ sebanyak 4 lembar. Dengan arah melebar dari ukuran aslinya. Untuk membuat pipa persegi, digunakan lem khusus (lem acrylic) yang dapat menyatukan sisi tebal dari plexiglass tersebut, mula-mula lembaran plexiglass yang telah dipotong pada masing-masing sisi tebalnya dijadikan satu sehingga membentuk sudut $90^{\circ}$ kemudian disuntik dengan lem acrylic pada bagian yang berhubungan. Begitu seterusnya sampai terbentuk pipa persegi.

Padapenyambunganseksiujidigunakansistem connectingpipe.Prosespenyambungannya yaitu pipa plexiglass yang mempunyai lebar $60 \mathrm{~mm}$ dan $50 \mathrm{~mm}$ dibuatkan suatu penahan karet dengan ukuran suaian paksa terhadap pipa, yang dimasukkan kedalam pipa plexiglass dengan kedalaman kurang lebih 3 - 4 mm. Sela-sela antara karet penahan dan dinding pipa plexiglass diolesi dengan lem silicon dengan tebal kurang lebih $1 \mathrm{~mm}$, hal ini dilakukan agar 
saat dilakukan pengecoran tidak terjadi kebocoran.

Untuk mendapatkan permukaan dalam cetakkan yang rata dan halus pada pipa plexiglass, maka digunakan mika plastik dengan tebal $1 \mathrm{~mm}$ yang dimasukkan kedalam pipa plexiglass dengan ukuran diameter sama dengan diameter masing-masing pipa plexiglass. Kemudian pipa plexiglass yang berukuran $40 \mathrm{~mm}$ dan $30 \mathrm{~mm}$ dimasukkan kedalam pipa plexiglass yang berukuran $60 \mathrm{~mm}$ dan $50 \mathrm{~mm}$, sebelumnya dibuat garis titik pusat pada mika plastik yang fungsinya untuk membuat sambungan tepat pada pusatnya. Kemudian disiapkan formula resin dan katalis, untuk dilakukan pengecoran pada pipa plexiglass yang telah dikondisikan. Untuk mengukur perubahan tekanan pada pengecilan pipa dibuat lubang dengan diameter $3 \mathrm{~mm}$ untuk dihubungkan dengan pipa manometer. Jumlah total dari titik pengukuran yang dibuat adalah 48 titik/lubang.

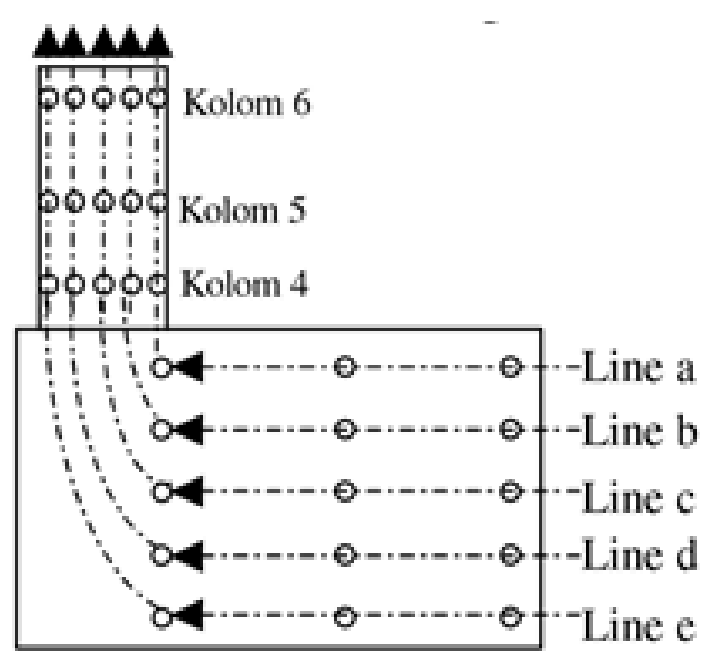

Kolom $3 \quad$ Kolom 2 Kolom 1

Gambar 7. Posisi lubang pandangan depan

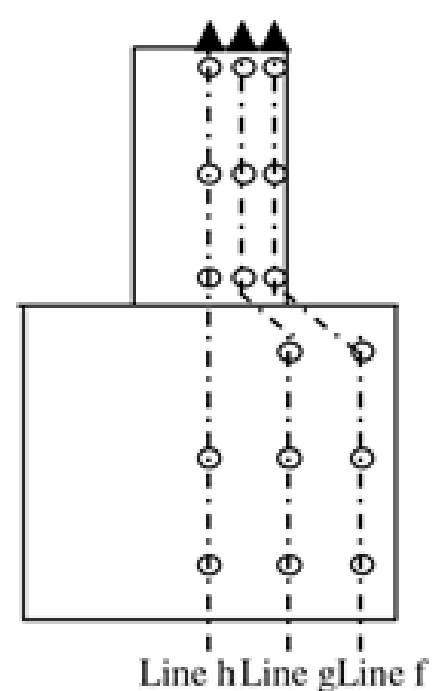

Gambar 8. Posisi lubang pandangan samping

\section{Bahan-bahan Penelitian}

Bahan-bahan yang diperlukan dalam penelitian ini adalah:

1. Fluida cair $=$ air bersih

2. Cairan berwarna = pewarna makanan 


\section{Alat-alat Penelitian}

1. Pompa, Digunakan untuk mengalirkan fluida dari bak penampungan I menuju rotameter, kemudian diteruskan ke seksi uji.

2. Flowmeter air Flowmeter atau Rotameter merupakan alat ukur debit aliran. Alat ini digunakan untuk mengetahui besar debit aliran yang mengalir didalam pipa, serta digunakan untuk membuat variasi debit dalam penlitian.

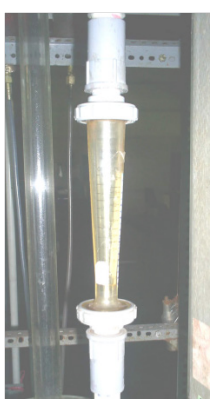

Gambar 9. Alat ukur Rotameter/Flow meter

3. Seksi uji, Seksi uji berupa Pipa persegi dengan belokan pada sudut $90^{\circ}$, dengan posisi Horizontal pada pipa besar (inlet) dan Vertikal pada pipa kecil (outlet). Ada 3 variasi pengecilan untuk digunakan dalam penelitian ini.

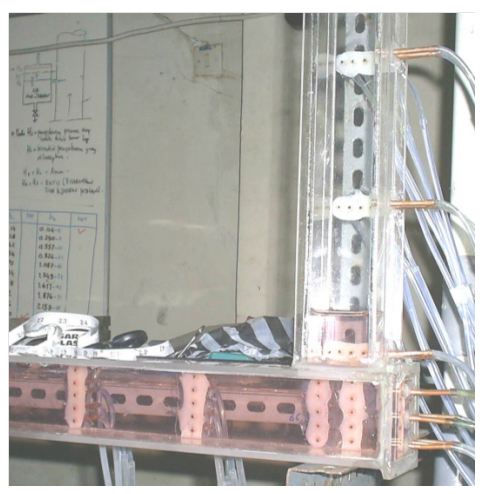

Gambar 10. Seksi uji

4. Manometer kolom air untuk mengukur beda tekanan pada seksi uji., Manometer kolom merupakan alat ukur untuk mengetahui nilai tekanan. Dalam penelitian ini akan digunakan manometer kolom air dengan jenis Piezometer. Alat ini dipilih karena faktor efisiensi dan kemudahan.

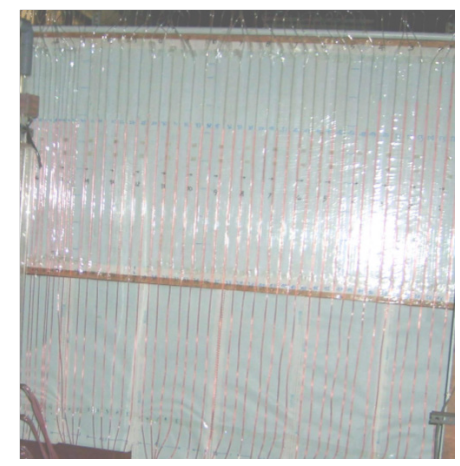

Gambar 11. Manometer kolom air (Piezometer) 
5. Bak penampung air sebagai tempat air yang akan dipompa ke seksi uji

6. Tempat menampung air setelah keluar dari seksi uji

7. Katup untuk mengatur debit air, ada 2 katup ; katup utama dan katup bypass.

8. Pipa PVC untuk saluran air

9. Gelas ukur kapasitas 2 liter.

\section{Instalasi Penelitian}

Susunan alat atau instalasi saluran untuk dilihat pada gambar 12

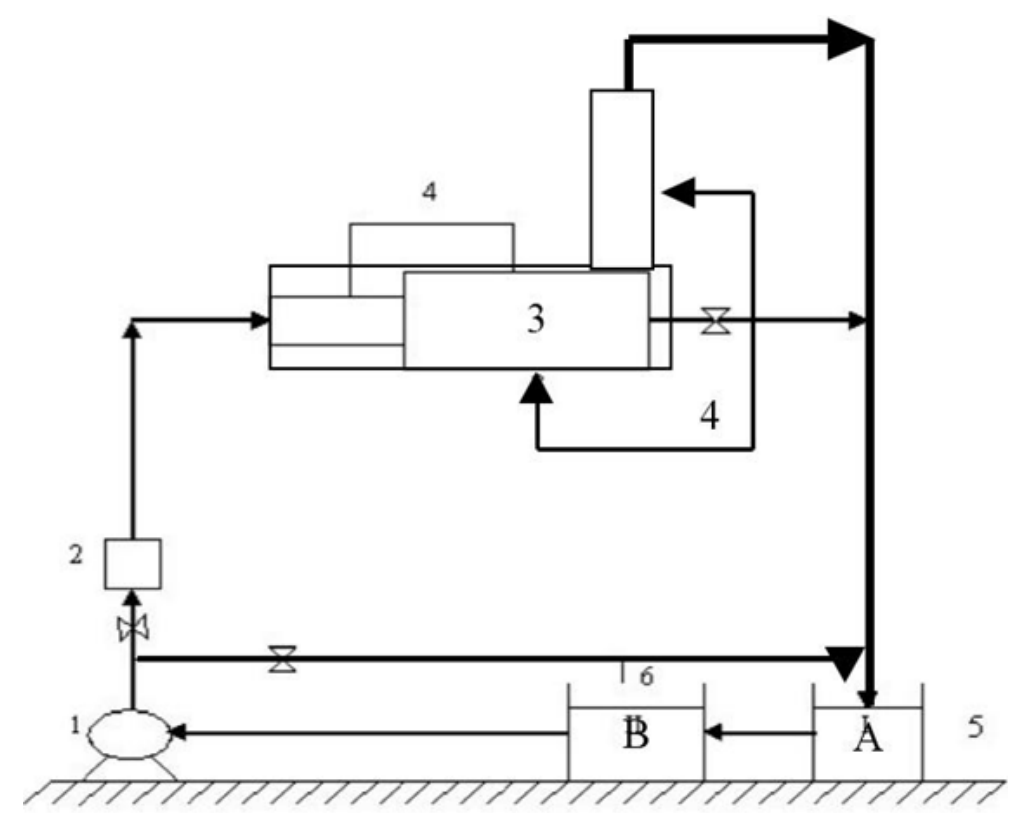

Keterangan :

1. Pompa

2. Rotameter

3. Seksi Uji

4. Manometer

5. Bak pembuangan air $\mathrm{A}$

6. Bak penampungan air $\mathrm{B}$

Gambar 12. Instalasi Peralatan Penelitian

Pada instalasi penelitian ini terdiri dari dua buah bak penampungan air, yakni bak penampungan air A dan bak penampungan air B. pemisahan ini dimaksudkan supaya air yang dipompa seminimal mungkin tidak terjadi gelembung atau pergolakan. Air yang dipergunakan diusahakan sebersih mungkin. Semua itu untuk menjaga dari kualitas air agar tidak terjadi hal-hal yang dapat mengganggu pergerakan aliran air.

Di bagian instalasi terdapat katubkatub (valve)yang terdapat di tiga tempat. Katub pertama terpasang sebagai katub by pass, dan katub kedua yaitu katub pengatur debit aliran yang menuju ke flowmeter yang akan mengalir menuju ke seksi uji. Fungsi katub by pass dalam penelitian ini adalah untuk mengatur debit aliran yang menuju flowmeter, agar air yang masuk ke seksi uji dapat memenuhi semua ruangan yang terdapat pada seksi uji.

Aliran fluida yang digunakan dalam penelitian ini adalah aliran fluida satu fase cair. Aliran fluida disuplai dari tangki penampungan air yang berkapasitas 60 liter yang dialirkan dengan pompa. Aliran air dikontrol dengan menggunakan kombinasi katub pengatur debit 
aliran dengan katub by pass dengan memperhatikan skala debit yang diinginkan pada flowmeter.

Perakitan seksi uji merupakan yang terpenting dan perlu perhatian guna mendapatkan ukuran yang presisi. Perakitan seksi uji ini dilaksanakan di Laboratorium Perpindahan Panas dan Massa PAU Pasca Sarjana Universitas Gajah Mada Yokyakarta.

\section{HASIL DAN PEMBAHASAN}

\section{Distribusi penurunan tekanan pada dinding depan sudden contraction}

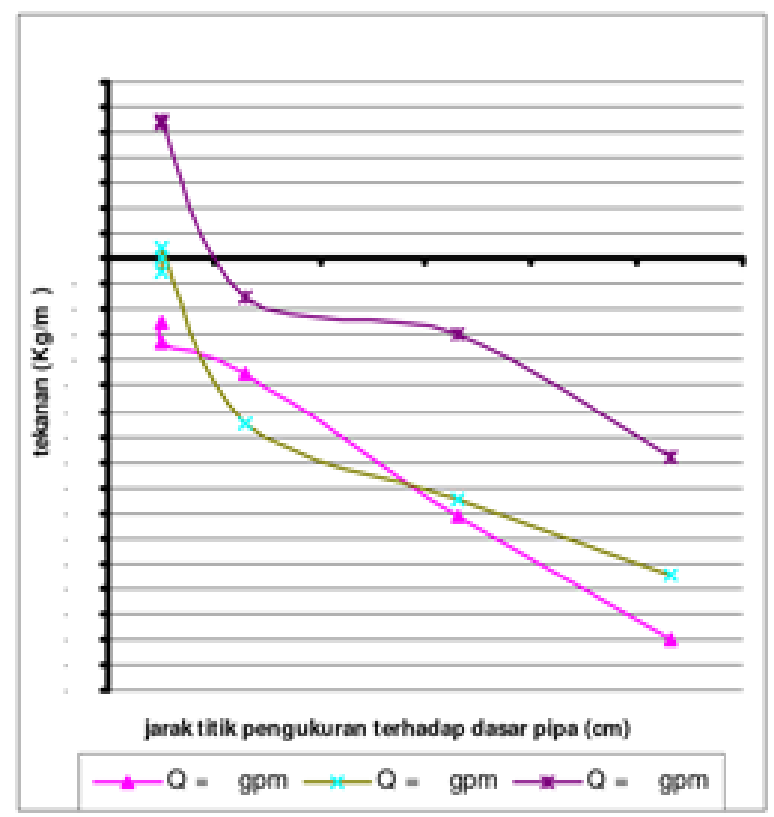

Gambar 13. Grafik penurunan tekanan terhadap jarak titik pengukuran dari dasar pipa, pada sumbu pipa (S) 0,6 bagian dinding depan

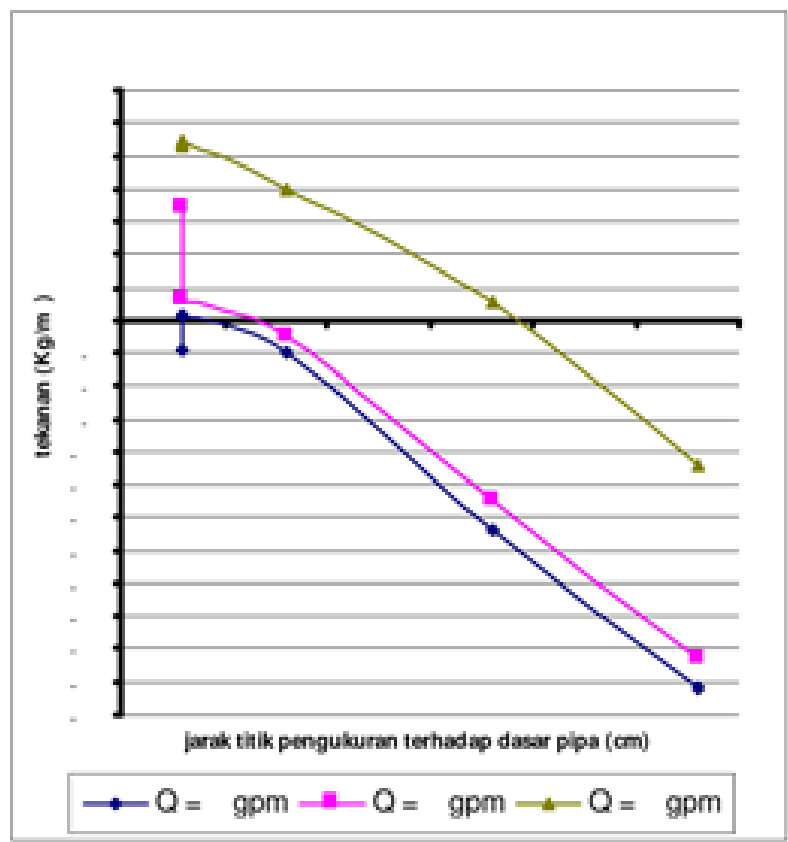

Gambar 14. Grafik penurunan tekanan terhadap jarak titik pengukuran dari dasar pipa, pada sumbu pipa (S) 0,667 bagian dinding depan 


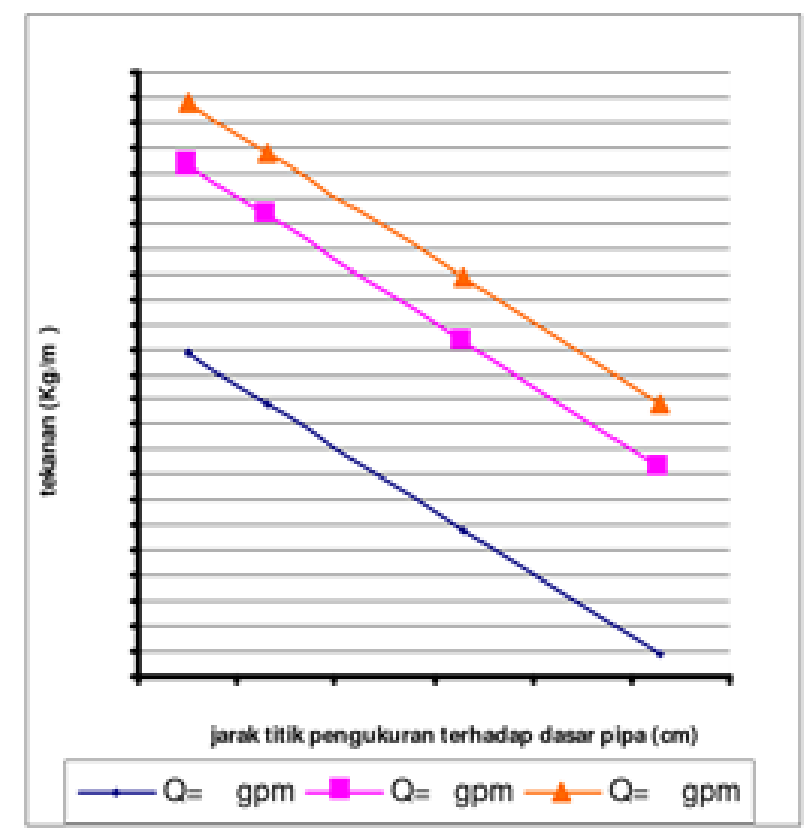

Gambar 15. Grafik penurunan tekanan terhadap jarak titik pengukuran dari dasar pipa, pada sumbu pipa (S) $0,0,8$ bagian dinding depan

Grafik penurunan tekanan pada sumbu saluran rasio $0.6,0.667$, dan 0.8 terlihat pada gambar 13, 14 dan 15. Sebagaimana terlihat, pada pipa inlet setelah mendekati belokan terjadi kenaikan tekanan yang disebabkan oleh perlambatan aliran. Kenaikan tekanan ini, mempunyai besar kenaikan yang kecil sehingga terlihat berimpit ketika digambarkan dalam grafik. Sementara itu, fenomena perlambatan tersebut terjadi karena adanya arus balik setelah aliran menumbuk ujung pipa inlet.

Pada aliran setelah melewati dinding kontraksi, terjadi penurunan tekanan hingga ujung pipa outlet. Besarnya penurunan tekanan antar line dalam pipa ini sangat kecil, sehingga terlihat berimpit dalam grafik. Penurunan tekanan pada kolom setelah dinding kontraksi disebabkan oleh adanya perubahan kecepatan dari $\mathrm{V}_{1}$ (pipa inlet) ke $\mathrm{V}_{2}$ (pipa outlet). Dan, penurunan tekanan pada kolom berikutnya dipengaruhi oleh posisi ketinggian titik pengukuran, semakin tinggi posisinya semakin rendah tekanannya.

\section{Distribusi penurunan tekanan pada dinding samping sudden contraction}




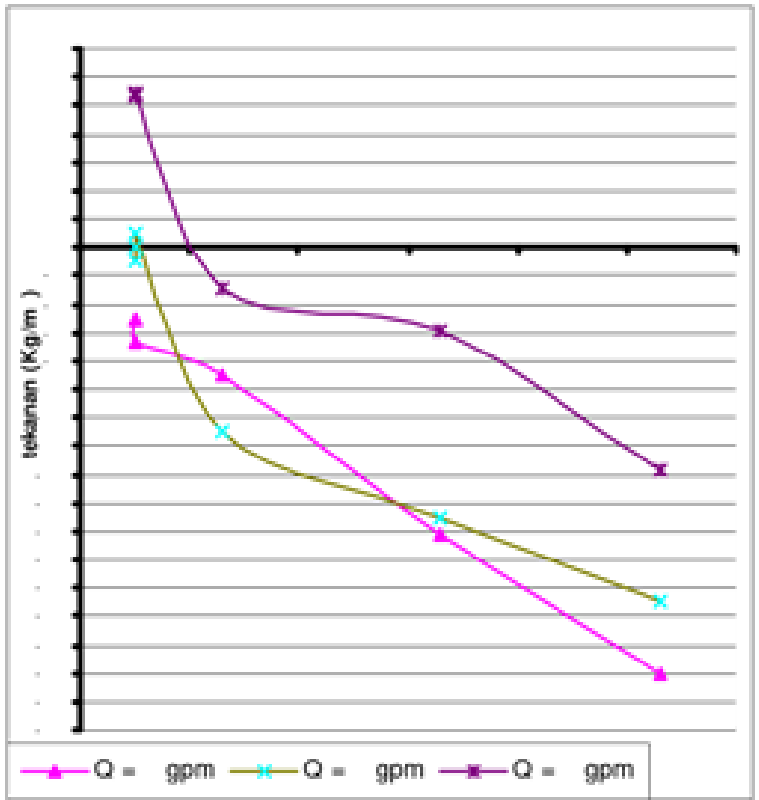

Gambar 16. Grafik penurunan tekanan terhadap jarak titik pengukuran dari dasar pipa, pada sumbu pipa (S) 0,6 bagian dinding samping

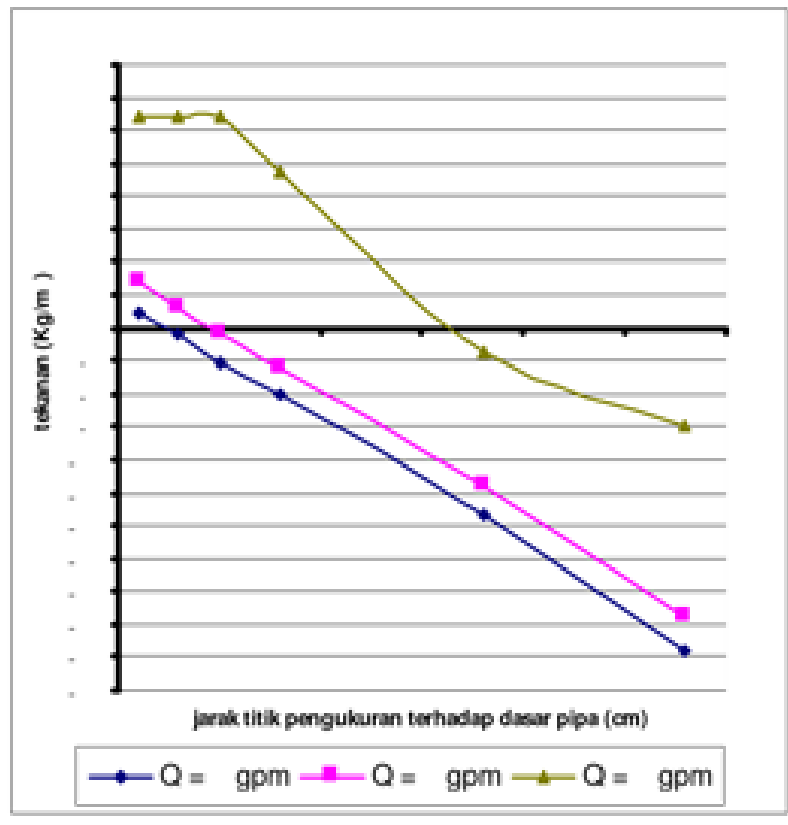

Gambar 17. Grafik penurunan tekanan terhadap jarak titik pengukuran dari dasar pipa, pada sumbu pipa (S) 0,667 bagian dinding samping 


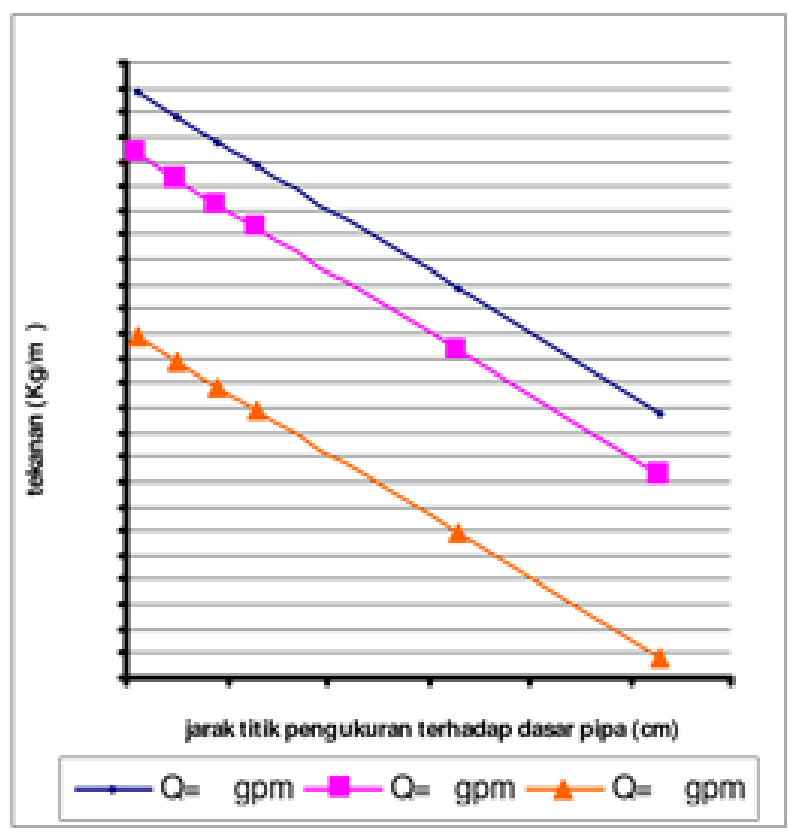

Gambar 18. Grafik penurunan tekanan terhadap jarak titik pengukuran dari dasar pipa, pada sumbu pipa (S) 0,8 bagian dinding samping

Gambar 16, 17, dan 18 memperlihatkan grafik perubahan tekanan pada pipa rasio 0.8 dengan debit aliran 2 GPM. Sebagaimana terlihat, pada pipa inlet terjadi penurunan tekanan akibat pengaruh rugi energi dan posisi ketinggian. Besarnya penurunan tekanan antar line dalam pipa ini sangat kecil, sehingga terlihat berimpit dalam grafik

Setelah melewati dinding kontraksi, penurunan tekanan terus terjadi hingga ujung saluran. Dan mempunyai perbedaan yang kecil antar linenya, sehingga terlihat grafik yang berimpit. Hal ini disebabkan oleh perubahan kecepatan dari V1 (pipa inlet) ke V2 (pipa outlet) dan dipengaruhi oleh posisi titik pengukuran, semakin tinggi posisinya semakin rendah tekanannya.

\section{Distribusi tinggi tekanan terhadap jarak dari sumbu saluran, pada dinding depan}

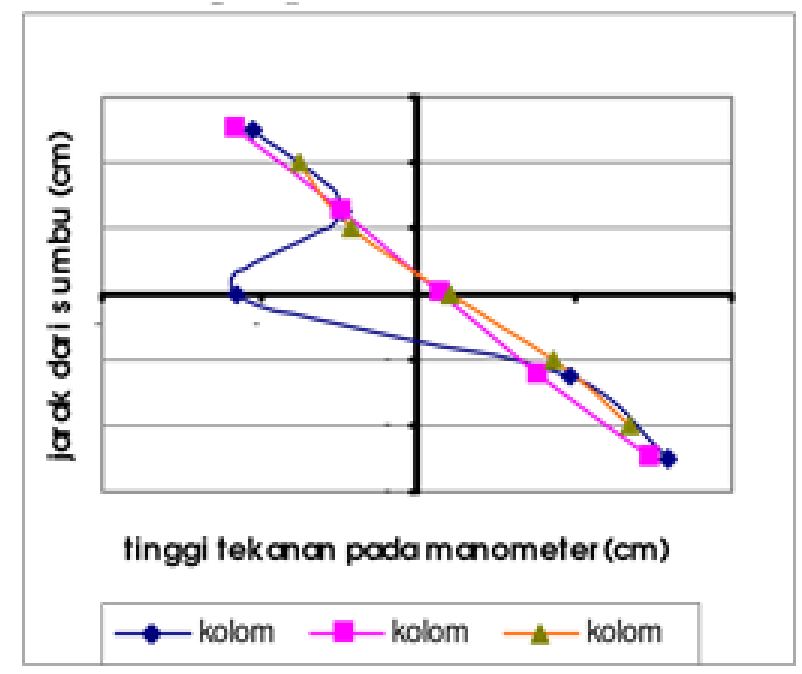

a. Inlet 


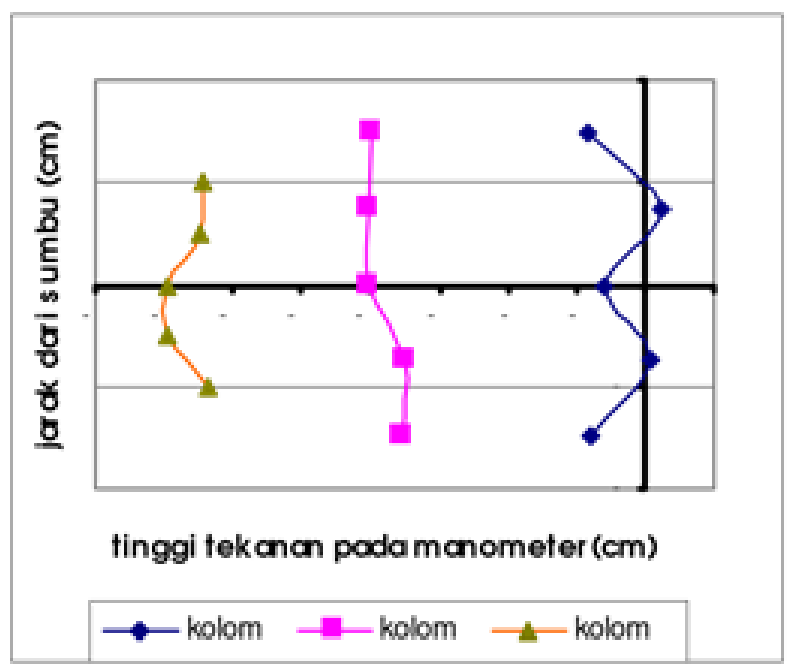

b. outlet

Gambar 19. Grafik distribusi tinggi tekanan terhadap jarak dari sumbu, pada pipa (S) 0,667 dan $\mathrm{Q}=2 \mathrm{gpm}$.

Sebagaimana terlihat dalam gambar 19, tinggi tekanan terbesar pada pipa inlet berada pada bagian bawah dinding dan yang terendah berada pada bagian atas. Profil ini terjadi pada ketiga kolom, dengan perbedaan yang kecil sehingga terlihat berimpit dalam grafik. Hal ini dipengaruhi oleh posisi ketinggian dan bentuk dinding saluran.

Setelah melewati dinding kontraksi, aliran yang terdekat dengan dinding mempunyai tinggi tekanan yang besar sedang pada sumbu saluran cenderung rendah. Hal ini terjadi karena adanya rugi energi akibat perlambatan pada dinding sedangkan pada sumbu saluran mempunyai kecepatan besar sehingga tekanannya rendah. Kecuali pada kolom 4, tinggi tekanan terbesar berada di antara dinding dan sumbu saluran, sementara pada tepi dinding dan sumbu saluran mempunyai tinggi tekanan yang hampr sama. Hal ini karena adanya pengaruh perubahan kecepatan setelah dinding kontraksi.

\section{Mendiskripsikan hubungan bilangan Reynolds (Re) terhadap debit aliran}

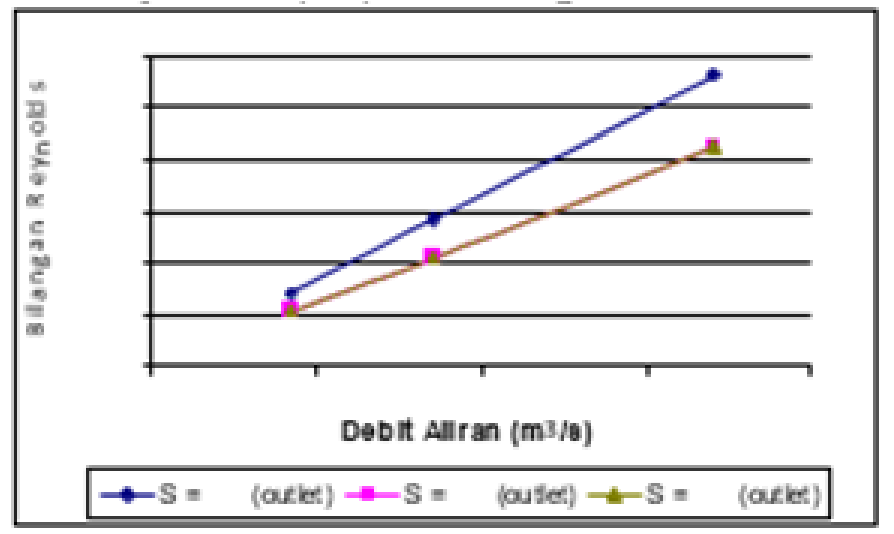

Gambar 20. Grafik hubungan bilangan Reynolds terhadap debit aliran

Pada grafik hubungan antara bilangan Reynolds (Re) dengan debit aliran (Q) yang ditunjukkan pada gambar 20. Sebagaimana terlihat, pada rasio perbesaran (S) : 0,6, 0,7 dan 0,8 terjadi peningkatan bilangan Reynolds sejalan dengan semakin besarnya debit aliran (Q) yang masuk pada saluran. Pada rasio perbesaran (S) 0,6, 0,7 dan 0,8, ketika di aliri dengan 
debit yang sama akan memiliki harga bilangan Reynolds yang berbeda.

Untuk rasio pengecilan $(\mathrm{S}) 0,6$ pipa inlet pada $\mathrm{Q}=0.000171 \mathrm{~m} 3 /$ det diperoleh harga $\mathrm{Re}$ $=3379.54$. Pada rasio perbesaran $(\mathrm{S}) 0,667$ pada $\mathrm{Q}=0.000171 \mathrm{~m}^{3} /$ det diperoleh harga $\mathrm{Re}$ $=4224.42$ dan untuk rasio pengecilan $(\mathrm{S}) 0,8$ pada debit $(\mathrm{Q})=0.000171 \mathrm{~m}^{3} /$ det diperoleh harga $\operatorname{Re}=4224.42$.

\section{KESIMPULAN}

Setiap kenaikan kecepatan selalu diikuti dengan penurunan tekanan, begitu juga sebaliknya. Pada pipa $(S)=0,6$ dengan debit 8 gpm, sebelum kontraksi mempunyai kecepatan $\left(\mathrm{v}_{1}\right)=0.0683 \mathrm{~m} / \mathrm{s}$ dan tekanan $109 \mathrm{Kg} / \mathrm{m}^{2}$ pada sumbu saluran (titik 3c), kemudian setelah melewati dinding kontraksi tekanan turun menjadi $-30 \mathrm{Kg} / \mathrm{m}^{2}$ pada kecepatan aliran $\left(\mathrm{v}_{2}\right)=$ $0.1896 \mathrm{~m} / \mathrm{s}$..

Terjadi peningkatan tekanan ketika mendekati belokkan (elbow) dengan sudut $90^{\circ}$ karena adanya perlambatan aliran.

Kenaikan tekanan dipengaruhi oleh kenaikan debit aliran (Q), pada debit aliran (Q) 4 GPM dalam saluran rasio 0,667, aliran masuk bertekanan $85 \mathrm{Kg} / \mathrm{m}^{2}$ ketika debit dinaikkan menjadi 8 GPM tekanan naik menjadi $133 \mathrm{Kg} / \mathrm{m}^{2}$.

Tekanan juga akan meningkat dengan semakin tingginya posisi titik pengukuran terhadap dasar saluran.

Semakin besar luas penampang pipa maka akan semakin kecil Bilangan Reynoldsnya, untuk rasio pengecilan 0,6 pipa outlet $\left(\mathrm{A}=0.0025 \mathrm{~m}^{2}\right)$ pada $\mathrm{Q}=0.000171 \mathrm{~m}^{3} /$ det diperoleh harga $\mathrm{Re}=3379.53795$, pada rasio pengecilan $0,667\left(\mathrm{~A}=0.0016 \mathrm{~m}^{2}\right)$ pada $\mathrm{Q}=0.000171 \mathrm{~m}^{3} /$ det diperoleh harga $\mathrm{Re}=4224.42244$ dan untuk rasio pengecilan 0,8 pipa outlet $(\mathrm{A}=0.0016$ $\mathrm{m}^{2}$ ) pada debit $(\mathrm{Q})=0.000171 \mathrm{~m}^{3} /$ det diperoleh harga $\mathrm{Re}=4224.42244$. Bilangan Reynolds juga akan naik seiring dengan besarnya debit aliran.

\section{DAFTAR PUSTAKA}

[1] Triatmodjo, Bambang, 1993, Hidraulika I, cetakan ke empat, Beta Offset, Yogyakarta.

[2] Sumarli, 2000, Studi aliran dua fase gas-cair melewati pengecilan saluran secara mendadak penampang segi empat, Tesis S-2, Jurusan Teknik Mesin Universitas Gadjah Mada Yogyakarta.

[3] Harjanta Yudi, 2003, Eksperimen Kehilangan Tenaga Aliran Akibat Koefisien Gesek Pipa, Tugas Akhir, Jurusan Teknik Mesin Universitas Muhammadiyah Surakarta.

[4] Dugdale, RH. 1986, Mekanika Fluida, edisi ketiga. Penerbit Erlangga. Jakarta.

[5] Sarjito, 2002, Studi Aliran Dua Fase Gas-Cair Melewati Pembesaran Saluran Secara Mendadak Pada Penampang Lingkaran, Tesis S-2, Jurusan Teknik Mesin Universitas Gadjah Mada Yogyakarta. 